\title{
Leuprorelin acetate affects adhesion molecule expression in human prostate cancer cells
}

\author{
CRISTIANA ANGELUCCI, GINA LAMA, FORTUNATA IACOPINO and GIGLIOLA SICA \\ Institute of Histology and Embryology, School of Medicine, \\ Catholic University of the Sacred Heart, I-00168 Rome, Italy
}

Received February 8, 2011; Accepted March 15, 2011

DOI: $10.3892 /$ ijo.2011.998

\begin{abstract}
Reduced cell-cell adhesion allows malignant epithelial cells to invade the basal membrane and penetrate the stroma. This implies the potential of the cells to escape from the primary tumor as well as spreading ability. Herein, we investigated the effects of leuprorelin acetate (LA), a GnRH agonistic analogue, alone or in combination with dihydrotestosterone (DHT), on the expression of molecules involved in cell adhesion (E-cadherin, N-cadherin, $\alpha-, \beta$ and $\gamma$-catenin) or in migration/invasion (c-met, CD44v6 and caveolin-1) in androgen-sensitive ( $\mathrm{LNCaP}$ ) and -insensitive (PC-3) prostate cancer $(\mathrm{CaP})$ cells. We demonstrated by immunoblotting that, in LNCaP cells, molecules present in the adherens junctions (E-cadherin, $\alpha-, \beta$ - and $\gamma$-catenin) were expressed, while $\alpha$-catenin was absent in PC-3 cells which expressed $\mathrm{N}$-cadherin and c-met. In LNCaP cells, no changes in E-cadherin levels were produced by $10^{-9} \mathrm{M}$ DHT while LA $\left(10^{-11}\right.$ or $\left.10^{-6} \mathrm{M}\right)$ up-regulated the protein level (up to $26-30 \%$ after $48 \mathrm{~h}$ ). In the same cells, $\beta$ - and $\gamma$-catenin expression was enhanced either by DHT ( 24 and $20 \%$, respectively) or LA (up to 18 and $40 \%$, respectively), while $\alpha$-catenin was not affected. Antagonistic effects were consistently observed between DHT and LA when the two hormones were jointly administered to the cells. Consistent results were obtained by immunocy tochemistry. Co-immunoprecipitation analysis, used to verify the integrity of the LNCaP cell adhesion complex, demonstrated the association of E-cadherin with catenins. In PC-3 cells, adhesion molecule expression, analyzed by immunoblotting, was unaffected by LA, while a down-regulation of c-met (up to 28\%) was observed after $24 \mathrm{~h}$ of treatment but which did not hold up over time (48-144 h). Our findings demonstrate the efficacy of LA in upregulating E-cadherin, $\beta$ - and $\gamma$-catenin in LNCaP cells. This effect, that may be
\end{abstract}

Correspondence to: Professor Gigliola Sica, Istituto di Istologia ed Embriologia, Facoltà di Medicina e Chirurgia, Università Cattolica del Sacro Cuore, Largo Francesco Vito 1, I-00168 Rome, Italy

E-mail: ibiis@rm.unicatt.it; gigliola@rm.unicatt.it

Key words: prostate cancer, leuprorelin acetate, dihydrotestosterone, E-cadherin, $\mathrm{N}$-cadherin, $\alpha$-catenin, $\beta$-catenin, $\gamma$-catenin considered as another aspect of the direct antitumor activity of the GnRH analogue in hormone-dependent $\mathrm{CaP}$ cells, may contribute to maintenance/restoration of the normal tissue architecture counteracting the tumor cell spreading tendency.

\section{Introduction}

During progression of solid tumors, malignant cells undergo a variation in their adhesion to other cells or components of the extracellular environment, which leads to substrate invasion and metastatic spread. Cell-cell and cell-matrix contacts are mediated by various families of adhesion molecules, which also influence cell motility, signaling, differentiation and apoptosis (1).

Cadherins are transmembrane glycoproteins which mediate $\mathrm{Ca}^{2+}$-dependent cell-cell adhesion in the majority of tissues (2). The most thoroughly investigated proteins within the cadherin family are E- and N-cadherin, found respectively in normal epithelia and in cells of mesenchymal origin (2). E-cadherin localizes to zonula adherens, and its expression plays a key role in the maintenance of epithelial integrity and polarized function (2). The adhesive properties of the cadherins have been shown to be dependent upon the ability of the intracellular domain to interact with cytoplasmic proteins of the catenin family ( $\alpha-, \beta$ - and $\gamma$-catenin) that bridge E-cadherin to the actin cytoskeleton $(2,3)$.

The E-cadherin/catenin adhesion system is impaired in cancer cells. In prostate cancer (CaP), as well as in other types of human tumors, a decrease or loss of E-cadherin has been observed which implicates an increasing invasive and metastatic potential as well as the dedifferentiation of cancer cells $(4,5)$. It also correlates with a poor prognosis (6), supporting a role for this protein as an 'invasion suppressor molecule' (7). Beside the loss of E-cadherin, the acquisition of epithelial cell motility during cancer progression is facilitated by the "cadherin switching', namely the gain in expression of non-epithelial cadherins such as N-cadherin or cadherin-11 (8). De novo expression of $\mathrm{N}$-cadherin has often been found in high grade $\mathrm{CaP}$ (8). The shift from an $\mathrm{E}$ - to $\mathrm{N}$-cadherin profile during $\mathrm{CaP}$ progression allows cancer cells to form $\mathrm{N}$-cadherin-mediated adhesion with neighboring $\mathrm{N}$-cadherin-expressing stromal cells thus facilitating metastasization (9).

Hepatocyte growth factor/scatter factor (HGF), a stromaderived protein that binds to the tyrosine kinase receptor 
c-met, is also involved in stromal-epithelial cell interaction (10). Accumulating evidence suggests an involvement of $\mathrm{HGF} / \mathrm{c}-\mathrm{met}$ overexpression in malignant cell migration and invasion in many types of cancers, including $\mathrm{CaP}$ (10). The scattering-promoting activity of c-met seems to involve its ability to reduce cadherin-mediated adhesion via tyrosine phosphorylation of cadherin-associated proteins (11). In malignant and nonmalignant cell lines, it has been demonstrated that c-met activation by HGF/SF as well as HGF-dependent cell scattering are strictly dependent on the presence of a member of the hyaluronan receptor family, the CD44 isoform containing variant exon v6 sequences (CD44v6) (12). This protein has been detected in androgen-insensitive, highly metastatic PC-3 cells, while androgen-sensitive, poorly metastatic LNCaP cells do not express this isoform (13). The correlation between CD44v6 expression and tumor invasiveness and/or progression in CaP is still unclear $(14,15)$.

The epithelial cell adhesive attitude may also be conditioned by non-adhesion molecules present at the plasma membrane. Caveolin-1 (Cav-1) is the main structural component of caveolae, vesicular invaginations of the plasmalemma. Cav-1 interacts with many signaling molecules regulating cell proliferation, differentiation, apoptosis, adhesion and invasion. Therefore, perturbations in Cav-1 expression and/ or function are hypothesized to play an important role in cancer pathogenesis. The significance of Cav-1 is still unclear in various types of human cancers, including $\mathrm{CaP}$; nevertheless, its up-regulation associates with metastases and poor prognosis (16).

It is well established that $\mathrm{GnRH}$ agonistic analogues mostly act as negative regulators of cell growth in several human malignancies such as breast, endometrial, ovarian and prostate cancer, which express GnRH receptors (GnRH-R) (17-21). In our experience, GnRH agonists are ineffective in regulating cell growth when used alone, but they counteract or suppress the stimulation of cell proliferation induced by estrogens in mammary and endometrial cancer cells (22-24) and by androgens or epidermal growth factor (EGF) in $\mathrm{CaP}$ cells (25). In the same CaP cells, we demonstrated the ability of the GnRH agonist, leuprorelin acetate (LA), to modulate the expression of various genes and/or proteins correlated with growth, differentiation and apoptosis and to up-regulate GnRH-R (25-29).

In this study, we investigated the effect of LA, alone or in combination with dihydrotestosterone (DHT), on the expression of the above described proteins (E-cadherin, N-cadherin, $\alpha-, \beta$ - and $\gamma$-catenin, c-met, CD44v6, Cav-1), involved in the setting of the adhesiveness/invasiveness of $\mathrm{CaP}$ cells. For this purpose, we used androgen-sensitive, poorly invasive LNCaP cells and androgen-insensitive, highly invasive and poorly differentiated PC-3 cells.

\section{Materials and methods}

Cell lines and culture conditions. Human androgen-sensitive LNCaP cells (passages 48-52) and androgen-insensitive PC-3 cells (passages 89-93) were cultured on 100-mm dishes in RPMI-1640 medium (Eurobio, Les Ulis Cedex B, France) and Dulbecco's modified Eagle's medium (DMEM, Eurobio), respectively. Human mammary carcinoma MCF-7 cells (used as positive control for E-cadherin, $\alpha-, \beta$ - and $\gamma$-catenin expression) were plated (at $5 \times 10^{4}$ cells $/ \mathrm{ml}$ ) on $100-\mathrm{mm}$ dishes and grown in DMEM, while human T-lymphoma Jurkat cells (used as a negative control for E-cadherin, $\alpha$-, $\beta$ - and $\gamma$-catenin expression) were seeded (at $1 \times 10^{5}$ cells $/ \mathrm{ml}$ ) into T-25 flasks and maintained in RPMI-1640. All culture media were supplemented with $10 \%$ foetal bovine serum (FBS; Life Technologies, Paisley, Scotland) (5\% for PC-3), antibiotics (100 IU/ml penicillin, $100 \mu \mathrm{g} / \mathrm{ml}$ streptomycin, Eurobio) and $2 \mathrm{mM}$ glutamine (Eurobio), and the cells were maintained in a humidified atmosphere of $5 \% \mathrm{CO}_{2}-95 \%$ air at $37^{\circ} \mathrm{C}$.

Hormones and growth factors. The GnRH analogue [D-Leu' ${ }^{6}$ $\left(\right.$ des-Gly $\left.{ }^{10}-\mathrm{NH}_{2}\right)$ ] LH-RH ethylamide (leuprorelin acetate, LA), was kindly donated by Takeda Italia Farmaceutici SpA, Rome, Italy. 5 $\alpha$-dihydrotestosterone (DHT) and EGF were purchased from Sigma-Aldrich (St. Louis, MO, USA). They were dissolved in saline solution (LA and EGF) or absolute ethanol (DHT) and stored at $4^{\circ} \mathrm{C}$.

Antibodies. Mouse monoclonal antibodies (mAbs) to E-cadherin (clone 4A2C7), $\alpha$-catenin (clone $\alpha \mathrm{CAT}-7 \mathrm{~A} 4)$, $\beta$-catenin (clone CAT-5H10), $\gamma$-catenin (clone 4F11) and CD44v6 (clone MA54) were from Zymed Laboratories (San Francisco, CA, USA); mAbs to N-cadherin (clone 32) and Cav-1 (clone 2297) were obtained from BD Transduction Laboratories (Lexington, KY, USA). Rabbit polyclonal Ab (pAb) to c-met (clone C12) was purchased from Santa Cruz Biotechnology (Santa Cruz, CA, USA). Mouse mAb to $\beta$-actin (clone AC-15) was from Sigma-Aldrich. The secondary horseradish peroxidase (HRP)-labeled Abs (goat anti-mouse and goat anti-rabbit $\mathrm{IgG}$ ) used in immunoblotting were from Vector Laboratories (Burlingame, CA, USA). A biotinylated secondary Ab (IgG goat anti-mouse) (Vector Laboratories) was used for immunocytochemical analysis.

\section{Cell treatments}

LNCaP cells. For Western blot and co-immunoprecipitation analysis, cells were plated out at a density of $5 \times 10^{4}$ cells $/ \mathrm{ml}$ of standard culture medium in 100-mm dishes. For immunocytochemistry, cells were seeded in standard medium at a density of $2.5 \times 10^{4}$ cells $/ \mathrm{ml}$, on microscope slides placed on the bottom of 12-well cell culture plates (Becton, Dickinson and Company, Franklin Lakes, NJ, USA). Cells were allowed to adhere, and $48 \mathrm{~h}$ after plating the medium was replaced with fresh RPMI-1640 supplemented with 5\% charcoal-treated FBS (CH-FBS) and containing LA $\left(10^{-11}\right.$ or $\left.10^{-6} \mathrm{M}\right)$, DHT $\left(10^{-9} \mathrm{M}\right)$ or their combination.

PC -3 cells. For Western blot analysis, cells were seeded at a density of $2.5 \times 10^{4}$ cells $/ \mathrm{ml}$ of standard culture medium in 100-mm dishes. Twenty-four hours later, as the cells adhered to the culture plates, the medium was renewed with DMEM supplemented with $5 \% \mathrm{CH}-\mathrm{FBS}$ and containing LA $\left(10^{-11}\right.$ or $\left.10^{-6} \mathrm{M}\right)$.

Medium of all cell lines was changed every $48 \mathrm{~h}$ while LA was added daily to the cultures. Treatments were stopped after $24,48,96$ or $144 \mathrm{~h}$ for Western blotting or after $48 \mathrm{~h}$ for co-immunoprecipitation analysis and immunocytochemistry. 


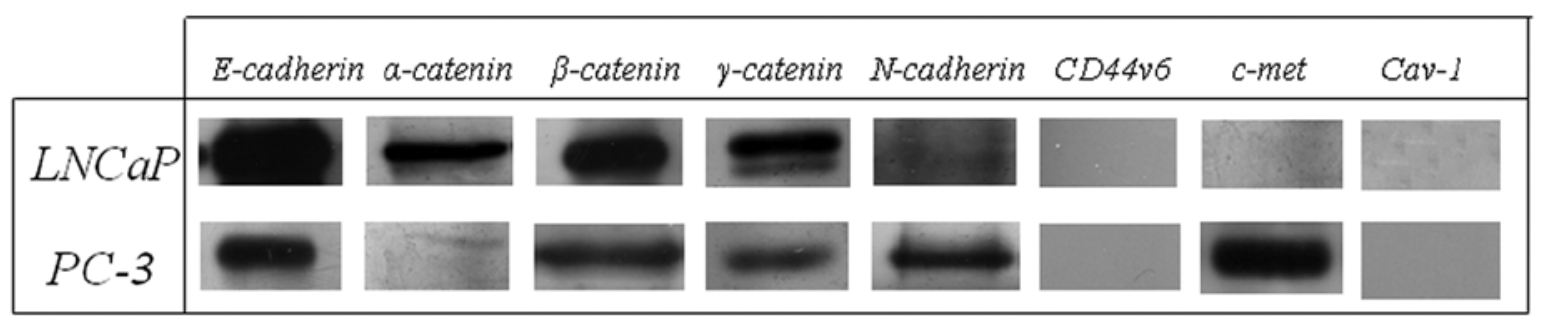

Figure 1. Western blot analysis showing the expression of a panel of adhesion/invasion proteins in LNCaP and PC-3 cells grown for $48 \mathrm{~h}$ in standard medium. Samples (50 $\mu \mathrm{g}$ of protein/lane) were electrophoresed on 8-12\% SDS-PAGE and blotted as described in Materials and methods.

Western blot analysis. At the end of each treatment period, LNCaP and PC-3 cells were lysed in RIPA buffer [50 mM Tris- $\mathrm{HCl}(\mathrm{pH} 7.7), 150 \mathrm{mM} \mathrm{NaCl}, 1 \%$ Triton $\mathrm{X}-100,1 \%$ sodium deoxycholate, $0.1 \%$ SDS] freshly supplemented with phosphatase and protease inhibitors $\left(100 \mu \mathrm{M} \mathrm{Na}_{3} \mathrm{VO}_{4}, 0.3 \mathrm{mM}\right.$ phenylmethylsulfonyl fluoride, $50 \mu \mathrm{g} / \mathrm{ml}$ leupeptin and $20 \mu \mathrm{g} /$ $\mathrm{ml}$ aprotinin) on ice, and the lysates were clarified by centrifugation at $12,000 \mathrm{rpm}$ for $10 \mathrm{~min}$ at $4^{\circ} \mathrm{C}$. Lysis of MCF-7 and Jurkat cells was performed using the same protocol. The total protein concentration was determined by a modification of the Lowry method (30). Samples containing $50 \mu \mathrm{g}$ of total protein were resolved on a 8-12\% SDS-PAGE and transferred onto an Immobilon P membrane (Millipore, Bedford, MA, USA) which was incubated ( $2 \mathrm{~h}$; at room temperature, RT) with the primary Abs (anti-E-cadherin, anti- $\alpha$-catenin, anti- $\beta$ catenin and anti-N-cadherin, 1:2,000; anti- $\gamma$-catenin, 1:5,000; anti-c-met and anti-Cav-1, 1:1,500; anti-CD44v6, 1:100) in TBS containing $0.02 \%$ Tween-20 and 5\% nonfat dried milk. The blots were then probed with the HRP-labeled secondary Abs ( $2 \mathrm{~h}$, at RT), and the protein bands were detected using an enhanced chemiluminescence system (ECL, Amersham, Buckinghamshire, UK) and visualized on Hyperfilm ECL (Amersham). The blots were stripped and rehybridized with an anti- $\beta$-actin mAb $(1: 10,000)$ used as an internal control for protein loading. The signals were quantitated by densitometric scanning (Chemi Doc Documentation System/Quantity One quantitation software; Bio-Rad Laboratories, Hercules, CA, USA). Densitometric units of the protein of interest were then corrected for the densitometric units of $\beta$-actin. The specific protein $/ \beta$-actin ratio from each treated sample was divided by the value obtained under control conditions to obtain the fold enhancement or reduction of the protein.

Co-immunoprecipitation (IP). To verify the association between E-cadherin and catenins and, hence, the integrity of the adhesion complexes, IP assays were performed on LNCaP cells. Cell extracts were prepared in RIPA buffer as defined above. Equal amounts of protein lysates $(0.5-1 \mathrm{mg})$ from the different samples were pre-cleared with Sepharose beads conjugated with protein $\mathrm{G}$ prior to the immunoprecipitation reactions, and beads were diluted with an equal volume of preimmune serum or TBS with $2.5 \%$ milk prior to use. For immunoprecipitation reaction, pre-cleared lysates, equalized to $500 \mu \mathrm{l}$ with lysis buffer, were incubated with the primary antibody (anti-E-cadherin) overnight at $4^{\circ} \mathrm{C}$, on a rocker. Then $50 \mu \mathrm{l}$ of the protein G-conjugated Sepharose beads was added, and this secondary reaction was continued to be mixed for $90 \mathrm{~min}$ at $4^{\circ} \mathrm{C}$. The beads were then pelleted $(10,000 \mathrm{rpm}$ at $4^{\circ} \mathrm{C}$ for $30 \mathrm{sec}$ ) and washed 4 times with $500 \mu \mathrm{l}$ of lysis buffer. Finally, $50 \mu \mathrm{l}$ of $1 \mathrm{X}$ Laemmli sample buffer was added to each pellet (washed beads), and samples heated at $100^{\circ} \mathrm{C}$ for 5 min. Immunoprecipitates were separated on $8 \%$ SDS-PAGE and transferred to membranes. Western blots were further processed as described above.

Immunocytochemistry. After $48 \mathrm{~h}$ of treatment, $\mathrm{LNCaP}$ cells were washed twice in PBS (without $\mathrm{Ca}^{2+}$ and $\mathrm{Mg}^{2+}$ ) and fixed with $3 \%$ paraformaldehyde for $20 \mathrm{~min}$ at RT. Endogenous peroxidase was inhibited with $3 \%$ hydrogen peroxide for $10 \mathrm{~min}$. Cells were incubated with the primary Abs (anti-Ecadherin, 1:200; anti- $\beta$-catenin, 1:200; anti- $\gamma$-catenin, 1:300) for $1 \mathrm{~h}$ at RT, and detection was performed using the Super Picture Polymer detection kit (Zymed Laboratories) for $45 \mathrm{~min}$ at RT. The chromogenic reaction was developed with 3,3'-diaminobenzidine (DAB substrate kit for peroxidase; Vector Laboratories) as chromogen. Harris hematoxylin was used for nuclear counterstaining. Negative controls were performed by omitting the primary Abs.

Cells were counted under a light microscope (Axioskop 2 Plus, Zeiss), and the staining intensity was graded as absent $(-)$, weak $(+)$, moderate $(++)$ and strong $(+++)$. Two independent observers counted at least 500 cells in 4-10 random fields per slide and the percentage of stained cells in each intensity category was determined.

The immunocytochemical analysis was scored in a semiquantitative fashion incorporating both the intensity and distribution of specific staining (H-score method). Scoring was generated as follows: [3 $\mathrm{x}$ (\% of strongly stained cells) $]+[2 \mathrm{x}$ (\% of moderately stained cells) $]+[1 \mathrm{x}(\%$ of weakly stained cells)] (31). This gave a possible range of 0-300. Scoring was performed on high-power fields (x400).

Statistical analysis. The significance of the difference between two groups of data obtained from Western blot experiments was determined by an unpaired two-tailed Student's t-test. Immunocytochemical data were analyzed by one-way ANOVA followed by Tukey's multiple comparison test. $\mathrm{p}<0.05$ was considered significant in all tests.

\section{Results}

Adhesion- and invasion-related protein expression in LNCaP and PC-3 cells. Fig. 1 shows the different pattern of expression of adhesion- and invasion-related molecules in LNCaP and 


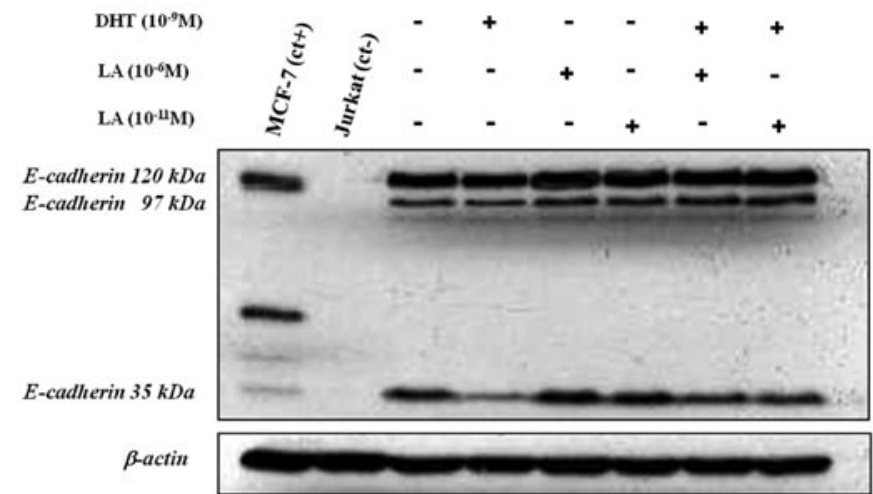

Figure 2. Western blot analysis of E-cadherin expression in LNCaP cells treated with DHT and LA (alone or combined) for $48 \mathrm{~h}$. Samples (50 $\mu \mathrm{g}$ of protein/lane) were electrophoresed on $8 \%$ SDS-PAGE and blotted as described in Materials and methods. MCF-7 and Jurkat cells were used as the positive control (ct+) and negative control (ct-) for E-cadherin, respectively. The intensity of the signals was quantified by densitometric scanning and normalized to that of $\beta$-actin. A representative blot from three separate experiments yielding similar results is shown.

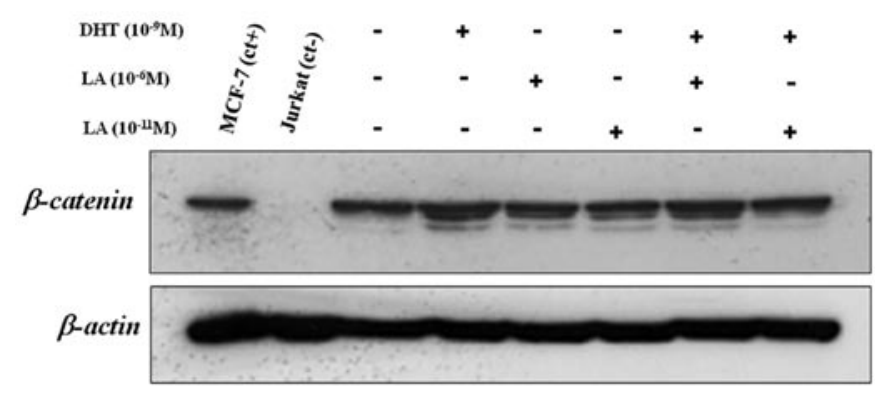

Figure 3. Western blot analysis of $\beta$-catenin expression in LNCaP cells treated with DHT and LA (alone or combined) for $48 \mathrm{~h}$. Samples $(50 \mu \mathrm{g}$ of protein/lane) were electrophoresed on $8 \%$ SDS-PAGE and blotted as described in Materials and methods. MCF-7 and Jurkat cells were used as the positive control (ct+) and negative control (ct-) for $\beta$-catenin, respectively. The intensity of the signals was quantified by densitometric scanning and normalized to that of $\beta$-actin. A representative blot from three separate experiments yielding similar results is shown.

PC-3 cells, which reflects their respective differentiation status. In particular, the androgen-sensitive and poorly invasive LNCaP cells expressed all of the proteins involved in the adhesion complex typical of epithelial cells (E-cadherin, $\alpha-, \beta$ - and $\gamma$-catenin) while none of the molecules related to a more aggressive phenotype $(\mathrm{N}$-cadherin, CD44v6, c-met, Cav-1) was detected in this model. The androgeninsensitive, highly invasive and poorly differentiated PC-3 cells showed an incomplete adhesion complex (E-cadherin, $\beta$ - and $\gamma$-catenin) but expressed molecules strictly related to invasiveness ( $\mathrm{N}$-cadherin and $\mathrm{c}$-met). In disagreement with findings by others (13), no expression of CD44v6 was noted in the PC-3 cells.

Expression of E-cadherin, $\alpha$-, $\beta$ - and $\gamma$-catenin in hormonetreated LNCaP cells

Western blot analysis. Treatment of LNCaP cells for 24, 48, 96 and $144 \mathrm{~h}$ with $10^{-9} \mathrm{M}$ DHT did not produce statistically significant variations in E-cadherin expression. On the other hand, LA $\left(10^{-11}\right.$ or $\left.10^{-6} \mathrm{M}\right)$ caused a slight increase in the

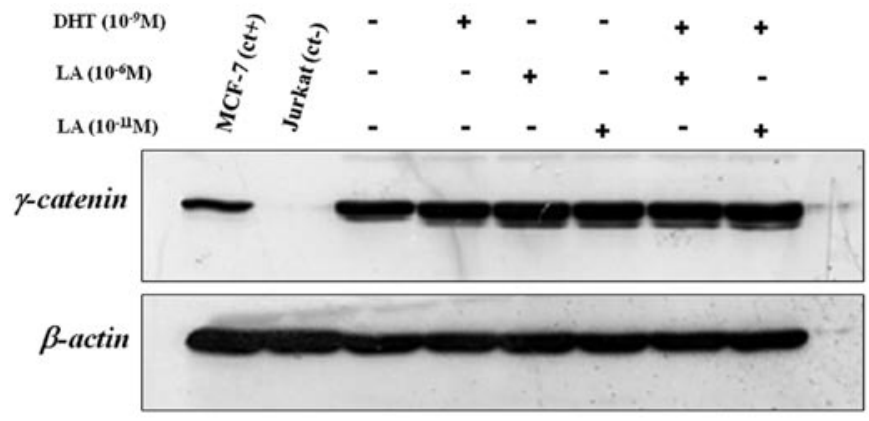

Figure 4. Western blot analysis of $\gamma$-catenin expression in LNCaP cells treated with DHT and LA (alone or combined) for $48 \mathrm{~h}$. Samples $(50 \mu \mathrm{g}$ of protein/lane) were electrophoresed on $8 \%$ SDS-PAGE and blotted as described in Materials and methods. MCF-7 and Jurkat cells were used as the positive control (ct+) and negative control (ct-) for $\gamma$-catenin, respectively. The intensity of the signals was quantified by densitometric scanning and normalized to that of $\beta$-actin. A representative blot from three separate experiments yielding similar results is shown.

E-cadherin level, which began after $24 \mathrm{~h}$ of treatment, reached $26-30 \%(\mathrm{p}<0.001)$ after $48 \mathrm{~h}$ and subsided as treatments were prolonged to 96 and $144 \mathrm{~h}$. The addition of DHT to LA significantly reduced the stimulatory effect of the analogue ( $<<0.02$, Fig. 2). Immunoblot analysis, carried out with an anti-E-cadherin antibody (clone 4A2C7) directed against the cytoplasmic domain of the human protein revealed two additional bands of approximately 97 and $35 \mathrm{kDa}$. Similar E-cadherin fragments, which have already been described $(32,33)$, probably arise from the cleavage of the cytoplasmic tail of the full length protein but their functional meaning is still unknown. DHT and LA treatments induced sometimes strong but fluctuating changes in their levels (Fig. 2). Cell treatment with an inhibitor of caspase 3, an enzyme which appears to be involved in the cleavage and shedding of the E-cadherin cytoplasmic domain (34), did not determine the disappearance of these additional signals (data not shown).

The expression of $\alpha$-catenin was not affected by any of the treatments considered (data not shown). Regarding $\beta$-catenin expression, both $10^{-9} \mathrm{M}$ DHT and LA $\left(10^{-11}\right.$ or $\left.10^{-6} \mathrm{M}\right)$ induced a slight protein increase $(24 \%, \mathrm{p}<0.01$ and $13-18 \%, \mathrm{p}<0.05$, respectively) only after $48 \mathrm{~h}$ (Fig. 3). When the two hormones were used together, a reduction in the stimulatory effect was observed (p<0.05, Fig. 3).

A similar trend was also observed in $\gamma$-catenin levels as the result of hormonal treatment. In fact, only a 48-h exposure to $10^{-9} \mathrm{M}$ DHT induced a weak signal increase $(20 \%, \mathrm{p}<0.02)$ while LA $\left(10^{-11}\right.$ or $\left.10^{-6} \mathrm{M}\right)$ caused an increase that reached $40 \%(\mathrm{p}<0.02)$ when the highest concentration was used. Combined treatment with DHT and LA significantly reduced the increase in $\gamma$-catenin levels when compared to those induced by the analogue ( $<<0.01$, Fig. 4).

Immunocytochemistry. The distribution of immunoreactive cells in all experimental groups was quantified by the H-score system and summarized in Tables I and II.

Immunocytochemistry of E-cadherin in LNCaP cells showed that the immunoreactivity was mainly localized at the plasma membrane level, with a weaker diffuse cytoplasmic labeling (Fig. 5). A strong immunostaining was noted in 
Table I. Semiquantitative immunocytochemical E-cadherin scores in LNCaP cells.

\begin{tabular}{lccccc}
\hline & \multicolumn{3}{c}{ Category of intensity } & & \\
\cline { 2 - 6 } Treatment & Negative & Weak & Moderate & Strong & H-score \\
\hline Untreated cells & $0.90 \pm 0.08$ & $50.34 \pm 0.20$ & $0.48 \pm 0.30$ & $48.38 \pm 0.09$ & $196.4 \pm 0.14$ \\
$10^{-9} \mathrm{M} \mathrm{DHT}$ & $0.31 \pm 0.07$ & $49.84 \pm 0.37$ & $0.31 \pm 0.06$ & $49.08 \pm 1.12$ & $197.7 \pm 2.80$ \\
$10^{-6} \mathrm{M} \mathrm{LA}$ & $0.56 \pm 0.26$ & $31.22 \pm 0.39$ & $3.57 \pm 0.58$ & $64.64 \pm 0.45$ & $232.3 \pm 0.56^{\mathrm{a}}$ \\
$10^{-11} \mathrm{M} \mathrm{LA}$ & $0.82 \pm 0.10$ & $32.64 \pm 0.09$ & $3.74 \pm 0.85$ & $62.92 \pm 0.48$ & $228.9 \pm 0.15^{\mathrm{a}}$ \\
$10^{-9} \mathrm{M} \mathrm{DHT}+10^{-6} \mathrm{M} \mathrm{LA}$ & $0.46 \pm 0.14$ & $44.34 \pm 0.41$ & $2.18 \pm 0.05$ & $52.98 \pm 0.37$ & $207.6 \pm 0.59^{\mathrm{b}, \mathrm{c}}$ \\
$10^{-9} \mathrm{M} \mathrm{DHT}+10^{-11} \mathrm{M} \mathrm{LA}$ & $0.45 \pm 0.15$ & $44.98 \pm 1.46$ & $2.40 \pm 0.06$ & $52.18 \pm 1.28$ & $206.3 \pm 2.50^{\mathrm{b}, \mathrm{d}}$ \\
\hline
\end{tabular}

Results are presented as mean \pm SD of two experiments. ${ }^{a} \mathrm{p}<0.001,{ }^{b} \mathrm{p}<0.01$ vs. untreated cells; ${ }^{\mathrm{c}} \mathrm{p}<0.001 \mathrm{vs} .10^{-6} \mathrm{M} \mathrm{LA} ;{ }^{\mathrm{d}} \mathrm{p}<0.001 \mathrm{vs} .10^{-11} \mathrm{M}$ LA; ANOVA and Tukey's multiple comparison tests.

Table II. Semiquantitative immunocytochemical $\gamma$-catenin scores in LNCaP cells.

\begin{tabular}{lccccc}
\hline & \multicolumn{4}{c}{ Category of intensity } \\
\cline { 2 - 5 } Treatment & Negative & Weak & Moderate & Strong & H-score \\
\hline Untreated cells & $1.00 \pm 0.05$ & $24.63 \pm 0.78$ & $32.46 \pm 0.65$ & $42.27 \pm 0.32$ & $216.4 \pm 0.46$ \\
$10^{-9}$ M DHT & $0.42 \pm 0.22$ & $3.73 \pm 0.43$ & $36.20 \pm 1.11$ & $49.66 \pm 0.45$ & $255.1 \pm 0.42^{\mathrm{a}}$ \\
$10^{-6} \mathrm{M} \mathrm{LA}$ & $1.07 \pm 0.24$ & $1.34 \pm 0.03$ & $27.82 \pm 0.82$ & $70.34 \pm 0.08$ & $268.0 \pm 1.35^{\mathrm{a}}$ \\
$10^{-11} \mathrm{M} \mathrm{LA}$ & $0.41 \pm 0.01$ & $3.85 \pm 0.14$ & $28.35 \pm 0.21$ & $67.39 \pm 0.33$ & $262.7 \pm 0.43^{\mathrm{a}}$ \\
$10^{-9} \mathrm{M}$ DHT $+10^{-6} \mathrm{M} \mathrm{LA}$ & $0.45 \pm 0.07$ & $4.96 \pm 0.21$ & $36.56 \pm 0.02$ & $58.12 \pm 0.11$ & $252.4 \pm 0.07^{\mathrm{a}, \mathrm{b}}$ \\
$10^{-9} \mathrm{M}$ DHT $+10^{-11} \mathrm{M} \mathrm{LA}$ & $0.56 \pm 0.04$ & $5.34 \pm 0.02$ & $36.24 \pm 0.10$ & $57.87 \pm 0.17$ & $251.4 \pm 0.28^{\mathrm{a}, \mathrm{c}}$ \\
\hline
\end{tabular}

Results are presented as mean \pm SD of two experiments. ${ }^{a} \mathrm{p}<0.001$ vs. untreated cells, ${ }^{b} \mathrm{p}<0.05$ vs. DHT or $10^{-6} \mathrm{M}$ LA; ${ }^{c} \mathrm{p}<0.05$ vs. DHT or $10^{-11} \mathrm{M}$ LA; ANOVA and Tukey's multiple comparison tests.

$\sim 50 \%$ of the untreated cells (cultured for $48 \mathrm{~h}$ ); the remaining cells were weakly positive, while a very small number $(<1 \%)$ of E-cadherin-negative and moderately positive cells was noted (Fig. 5a). A 48-h treatment with $10^{-9} \mathrm{M}$ DHT did not induce any variations in the described cell categories. When a comparison was made between untreated and LA-treated cells, H-score analysis revealed that both concentrations of the analogue $\left(10^{-11}\right.$ or $\left.10^{-6} \mathrm{M}\right)$ promoted a significant increase in E-cadherin immunostaining $(\sim 18 \%$, p $<0.001$; Fig. $5 \mathrm{c}$ and d). This latter effect was reduced by the combined treatment (p<0.001; Fig. 5e and f).

Regarding $\gamma$-catenin expression, LNCaP cells showed a cytoplasmic reactivity, which was stronger just underneath the cell membrane (Fig. 6). The untreated cell population was entirely immunopositive with various degrees of staining intensity: strong $(\sim 42 \%)$, moderate $(\sim 32 \%)$ or weak $(\sim 25 \%)$ (Fig. 6a). H-scoring showed that DHT treatment led to a detectable increase in $\gamma$-catenin immunolabeling $(18 \%$, $\mathrm{p}<0.001$; Fig. 6b). Comparable effects were observed as a result of treatment with LA $\left(10^{-11}\right.$ or $10^{-6} \mathrm{M}$ ) (up to $24 \%$, p $<0.001$; Fig. $6 \mathrm{c}$ and d). Combined exposure of LNCaP cells to DHT and LA caused a clear reduction in the described stimulatory effects ( $p<0.05$; Fig. 6e and $\mathrm{f}$ ). $\beta$-catenin showed a pattern of expression analogous to that of $\gamma$-catenin, even though the changes observed were less pronounced compared to those in $\gamma$-catenin levels (data not shown).

Expression of $E$-cadherin, $\beta$ - and $\gamma$-catenin, $N$-cadherin and c-met in LA-treated PC-3 cells

Western blot analysis. In the androgen-independent cells, treatment with LA $\left(10^{-11}\right.$ or $\left.10^{-6} \mathrm{M}\right)$ did not affect the expression of E-cadherin $(120,97$ and $35 \mathrm{kDa}), \beta$-catenin, $\gamma$-catenin and $\mathrm{N}$-cadherin (data not shown). c-met expression appeared to be down-regulated (up to $\sim 30 \%, \mathrm{p}<0.05$ ) only after $24 \mathrm{~h}$ of treatment with the analogue, while it remained unchanged at the subsequent time intervals (Fig. 7).

Adhesion complex integrity. IP analysis of E-cadherincatenin interaction was performed in LNCaP cells which, unlike PC-3 cells, express all elements of the adhesion complex.

Using an anti-E-cadherin monoclonal antibody (4A2C7), $\alpha-, \beta$-, and $\gamma$-catenin were co-immunoprecipitated from the whole protein lysate demonstrating the integrity of the adhesion complex (Fig. 8). 

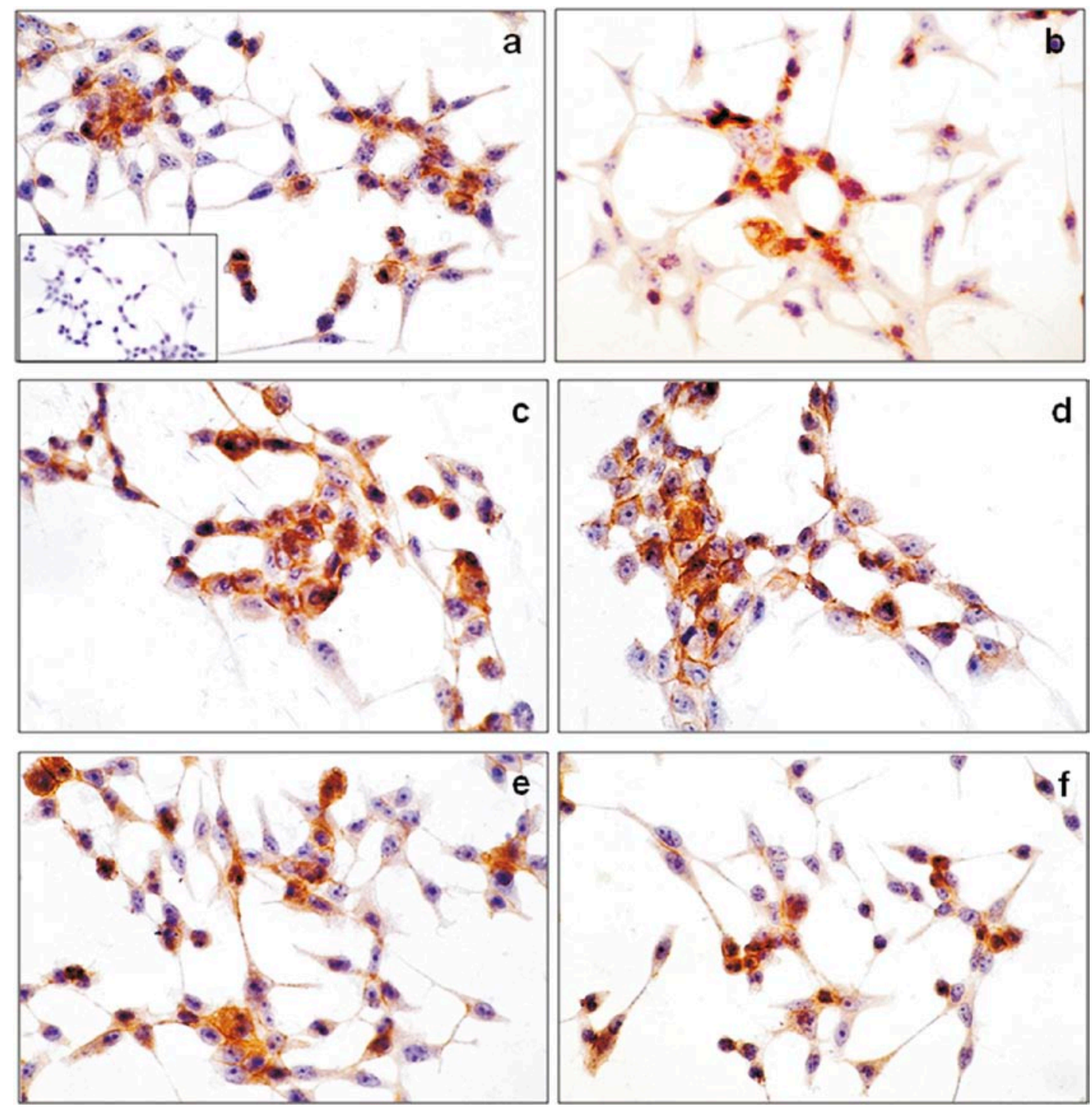

Figure 5. Immunocytochemical analysis of E-cadherin expression in LNCaP cells exposed for $48 \mathrm{~h}$ to DHT and LA. (a) Untreated cells, (b) $10^{-9} \mathrm{M}$ DHT, (c) $10^{-6} \mathrm{M} \mathrm{LA}$, (d) $10^{-11} \mathrm{M} \mathrm{LA}$, (e) $10^{-9} \mathrm{M}$ DHT $+10^{-6} \mathrm{M} \mathrm{LA}$, (f) $10^{-9} \mathrm{M}$ DHT $+10^{-11} \mathrm{M}$ LA. The inset in the photomicrograph of the untreated cells shows a negative control. The images are representative of two independent experiments yielding similar results. Original magnification, $\mathrm{x} 400$.

\section{Discussion}

The crucial molecular events leading to the invasive potential and metastatic spread of cancer cells include disruption of cell-cell adhesion and aberrant expression of invasion-related molecules (1). Cadherins and catenins, as essential components of the adherens junctions, mediate cell-cell adhesion and regulate cell motility in many types of cancers such as $\mathrm{CaP}$. As another potential aspect of the well-known antitumor direct activity of $\mathrm{GnRH}$ agonists, we investigated the ability of LA to affect the expression of cadherin/catenin adhesion molecules as well as that of other proteins involved in the acquisition of a metastatic phenotype.

The results of the present study demonstrated that LA and DHT were able to up-regulate E-cadherin/catenin expression in androgen-sensitive and poorly invasive $\mathrm{CaP}$ cells wherein none of the investigated invasion-related molecules was detected. In the androgen-insensitive, less differentiated and highly invasive PC-3 cells, which express a defective adhesion complex, only c-met protein was transiently affected by treatment with LA.

Regarding E-cadherin expression, both the cell lines exhibited the full length protein $(120 \mathrm{kDa})$ and two truncated forms $(\sim 97$ and $\sim 35 \mathrm{kDa}$ ) which were also identified by others $(32,33)$ but whose origin and role are still being debated. Since some of the E-cadherin fragments appeared to originate from proteolytic cleavage of the functional protein by various caspases/metalloproteinases, we demonstrated that caspase 3 was not involved in their production. This enzyme was previously demonstrated to be responsible for the cleavage of the cytoplasmic tail of E-cadherin (34), the domain against which the antibody used in the present study (4A2C7) was directed. Nevertheless, in our study, inhibition of the enzymatic activity of caspase 3 did not determine the disappearance of any of the fragments.

Normal E-cadherin expression plays a key role in the maintenance of epithelial integrity and polarized function $(35,36)$. E-cadherin is down-regulated and tightly associ- 

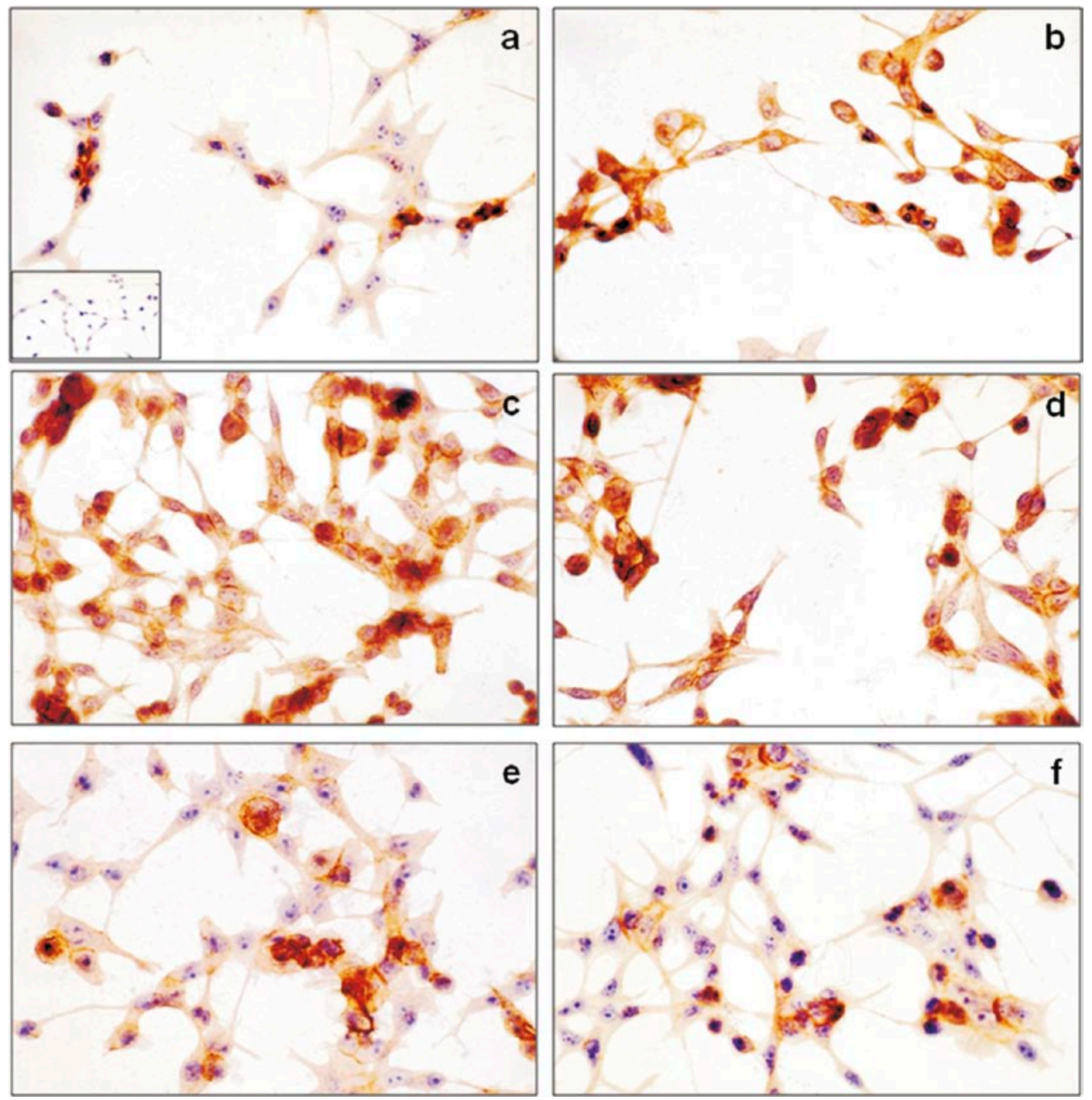

Figure 6. Immunocytochemical analysis of $\gamma$-catenin expression in LNCaP cells exposed for $48 \mathrm{~h}$ to DHT and LA. (a) Untreated cells, (b) $10^{-9} \mathrm{M}$ DHT, (c) $10^{-6} \mathrm{M} \mathrm{LA}$, (d) $10^{-11} \mathrm{M} \mathrm{LA}$, (e) $10^{-9} \mathrm{M}$ DHT $+10^{-6} \mathrm{M}$ LA, (f) $10^{-9} \mathrm{M}$ DHT $+10^{-11} \mathrm{M}$ LA. The inset in the photomicrograph of the untreated cells shows a negative control. The images are representative of two independent experiments yielding similar results. Original magnification, $\mathrm{x} 400$.

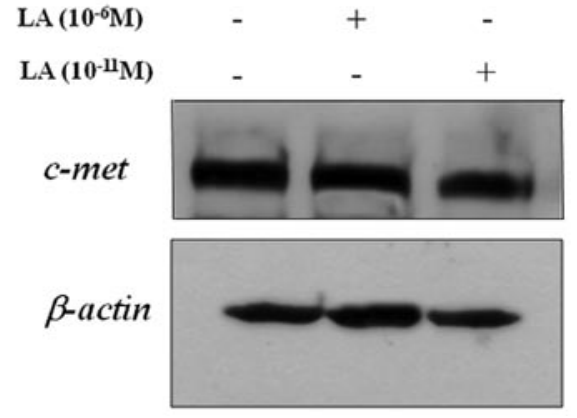

Figure 7. Western blot analysis of c-met expression in PC-3 cells treated with LA $\left(10^{-11}\right.$ or $\left.10^{-6} \mathrm{M}\right)$ for $48 \mathrm{~h}$. Samples $(50 \mu \mathrm{g}$ of protein/lane) were electrophoresed on $8 \%$ SDS-PAGE and blotted as described in Materials and methods. The intensity of the signals was quantified by densitometric scanning and normalized to that of $\beta$-actin. A representative blot from three separate experiments yielding similar results is shown.

ated with tumor invasion and metastasis in multiple human cancer types, and its role as an invasion suppressor molecule has been proven (4-7). Our results from immunoblot and immunocytochemical analyses demonstrated that DHT did not affect the expression of E-cadherin in LNCaP cells after 24-144 h of treatment. Our data disagree in part with those previously reported by Carruba et al who observed in the same model a strong increase in E-cadherin levels induced by DHT, as well as by the synthetic androgen R1881 (37). The discrepancy may be attributable to the different durations of treatment $(72 \mathrm{~h})$ and/or to the authors' use of the cell culture at early passages.

In the same cell line, we demonstrated that treatment with DHT elicited an increase in $\beta$ - and $\gamma$-catenin. This effect may contribute to the stabilization of the adhesion complexes or may otherwise enrich the cytoplasmic pool of free catenins which are known to be responsible for the activation of mitogenic signaling pathways $(38,39)$. These latter events agree with androgen-induced $\mathrm{CaP}$ cell proliferation $(25,28)$. In regards to the LA effect in androgen-sensitive cells, to our knowledge, our results represent the first evidence of the efficacy of a GnRH agonist in inducing the expression of E-cadherin, $\beta$ - and $\gamma$-catenin. This event may contribute to 


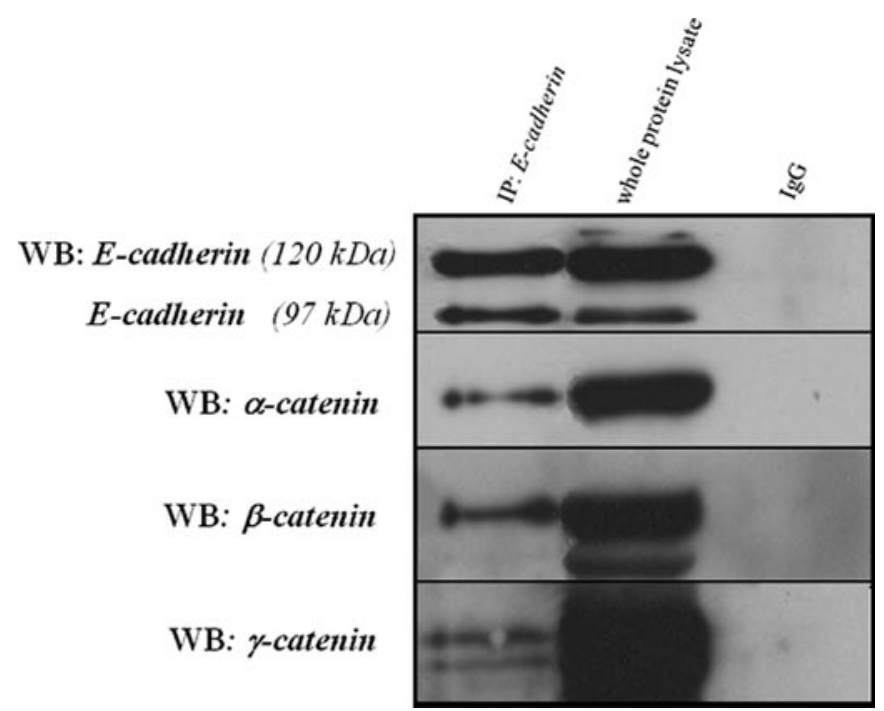

Figure 8. Co-immunoprecipitation of the E-cadherin and $\alpha$-, $\beta$-, and $\gamma$-catenin complex. LNCaP cells, cultured for $48 \mathrm{~h}$ in standard medium, were harvested and lysed, and proteins were immunoprecipitated with the monoclonal antibody anti-E cadherin (clone 4A2C7) or IgG control. Lane 1, E-cadherin immunoprecipitates; lane 2, whole cell lysate; line 3, IgG immunoprecipitates (negative control). Western blotting (WB) was carried out using antibodies against E-cadherin (clone 4A2C7), $\alpha$-catenin (clone $\alpha \mathrm{CAT}-7 \mathrm{~A} 4), \beta$-catenin (clone CAT-5H10) and $\gamma$-catenin (clone 4F11).

the maintenance of epithelium integrity, limiting the ability of tumor cells to invade and metastasize. Efficacy in inhibiting growth factor-induced cell migration and/or invasion in androgen-independent $\mathrm{CaP}$ cells has been previously demonstrated for GnRH agonistic analogues $(40,41)$. In particular, the ability of LA to counteract IGF-I-stimulated cell migration and invasion has been demonstrated in DU-145 cells. In this model, the authors also showed that the analogue was able to abolish IGF-I-induced stimulation of $\alpha v \beta 3$ integrin whose expression correlates with the aggressive and invasive behavior of CaP cells (41).

The interference which occurred between DHT and LA activity in relation to adhesion protein expression is not unexpected since it transpired in almost every study we carried out with LA combined with various hormones or growth factors. In fact, antagonistic effects were observed on tumor cell growth as well as on the expression of PSA, MAP kinases, apoptosis-related genes and GnRH-R (22-29). The molecular basis of the interference between DHT and LA is still unclear but conceivably could be ascribed to the analogue targeting of the androgen receptor (AR) signaling. In fact, Maudsley et al (42) demonstrated a novel GnRH pathway existing in LNCaP and PC-3 cells, which leads to the nuclear translocation of AR and renders it transcriptionally inactive.

The lack of a significant effect of LA on E-cadherin/ catenin expression in the androgen-insensitive PC-3 cells may be due to either their poorly differentiated status or their highly invasive behavior which is the reason for the disability of the analogue to affect cell-cell adhesion in the later stages of prostate tumor progression, once the threshold of androgen-independence has been surpassed. However, the analogue-induced transient reduction in c-met level may suggest a certain influence of the hormone on the expression of those proteins more closely linked to invasive processes.

In conclusion, our study provides initial evidence of the up-regulation of E-cadherin and catenins by a GnRH agonistic analogue in androgen-sensitive CaP cells. This direct effect on cell-cell adhesion appears to result in an improvement in tumor epithelium integrity, which consequently limits cell spreading and metastasization as demonstrated by the intactness of the cadherin/catenin adhesion complex. Moreover, our results are in agreement with the in vivo antitumor activity of the analogue since the stimulatory effect on adhesion molecules occurred even at a low concentration, achievable after commonly used therapeutic administrations. Our study also demonstrates the inefficacy of the analogue in improving the adhesive status of poorly differentiated, highly invasive androgen-insensitive CaP cells. Further investigations are needed to better clarify the effect of the analogue on the free pool of $\beta$-catenin and its phosphorylation status which are strongly involved in tumor cell growth.

\section{Acknowledgements}

This research was supported in part by a grant from 'Ministero dell'Istruzione, dell'Università e della Ricerca' (MM06575531).

\section{References}

1. Mareel M and Leroy A: Clinical, cellular, and molecular aspects of cancer invasion. Physiol Rev 83: 337-376, 2003.

2. Stemmler MP: Cadherins in development and cancer. Mol Biosyst 4: 835-850, 2008.

3. Ozawa M, Ringwald M and Kemler R: Uvomorulin-catenin complex formation is regulated by a specific domain in the cytoplasmic region of the cell adhesion molecule. Proc Natl Acad Sci USA 87: 4246-4250, 1990.

4. Birchmeier W and Behrens J: Cadherin expression in carcinomas: role in the formation of cell junctions and the prevention of invasiveness. Biochim Biophys Acta 1198: 11-26, 1994.

5. Prasad S, Thraves P, Kuettel M and Dritschilo A: Cytoskeletal and adhesion protein changes during neoplastic progression of human prostate epithelial cells. Crit Rev Oncol Hematol 27: 69-79, 1998.

6. Giroldi LA, Shimazui T, Schalken JA, Yamasaki H and Bringuier PP: Classical cadherins in urological cancers. Morphologie 84: 31-38, 2000.

7. Vleminckx K, Vakaet L Jr, Mareel M, Fiers W and van Roy F: Genetic manipulation of E-cadherin expression by epithelial tumor cells reveals an invasion suppressor role. Cell 66: 107-119, 1991.

8. Tomita K, van Bokhoven A, van Leenders GJ, Ruijter ET, Jansen CF, Bussemakers MJ and Schalken JA: Cadherin switching in human prostate cancer progression. Cancer Res 60: 3650-3654, 2000.

9. Tran NL, Nagle RB, Cress AE and Heimark RL: N-cadherin expression in human prostate carcinoma cell lines. An epithelialmesenchymal transformation mediating adhesion with stromal cells. Am J Pathol 155: 787-798, 1999.

10. Jiang W, Hiscox S, Matsumoto K and Nakamura T: Hepatocyte growth factor/scatter factor, its molecular, cellular and clinical implications in cancer. Crit Rev Oncol Hematol 29: 209-248, 1999.

11. Shibamoto S, Hayakawa M, Takeuchi K, et al: Tyrosine phosphorylation of beta-catenin and plakoglobin enhanced by hepatocyte growth factor and epidermal growth factor in human carcinoma cells. Cell Adhes Commun 1: 295-305, 1994.

12. Orian-Rousseau V, Chen L, Sleeman JP, Herrlich P and Ponta H: CD44 is required for two consecutive steps in HGF/c-Met signaling. Genes Dev 16: 3074-3086, 2002.

13. Lokeshwar BL, Lokeshwar VB and Block NL: Expression of CD44 in prostate cancer cells: association with cell proliferation and invasive potential. Anticancer Res 15: 1191-1198, 1995. 
14. Gu H, Shang P and Zhou C: Expression of CD44v6 and E-cadherin in prostate carcinoma and metastasis of prostate carcinoma. Zhonghua Nan Ke Xue 10: 32-34, 2004.

15. Aaltomaa S, Lipponen P, Ala-Opas M and Kosma VM: Expression and prognostic value of CD44 standard and variant v3 and v6 isoforms in prostate cancer. Eur Urol 39: 138-144, 2001.

16. Cohen AW, Hnasko R, Schubert W and Lisanti MP: Role of caveolae and caveolins in health and disease. Physiol Rev 84: 1341-1379, 2004

17. Miller WR, Scott WN, Morris R, Fraser HM and Sharpe RM: Growth of human breast cancer cells inhibited by a luteinizing hormone-releasing hormone agonist. Nature 313: 231-233, 1985.

18. Emons G, Schroeder B, Ortmann O, Westphalen S, Schulz KD and Schally AV: High affinity binding and direct antiproliferative effects of luteinizing hormone-releasing hormone analogs in human endometrial cancer cell lines. J Clin Endocrinol Metab 77: 1458-1464, 1993 .

19. Emons G, Ortmann O, Becker M, et al: High affinity binding and direct antiproliferative effects of LHRH analogues in human ovarian cancer cell lines. Cancer Res 53: 5439-5446, 1993.

20. Qayum A, Gullick W, Clayton RC, Sikora K and Waxman J: The effects of gonadotrophin releasing hormone analogues in prostate cancer are mediated through specific tumour receptors. Br J Cancer 62: 96-99, 1990

21. Limonta P, Dondi D, Moretti RM, Maggi R and Motta M: Antiproliferative effects of luteinizing hormone-releasing hormone agonists on the human prostatic cancer cell line LNCaP. J Clin Endocrinol Metab 75: 207-212, 1992.

22. Sica G, Iacopino F, Robustelli della Cuna G, Marchetti P and Marini L: Combined effects of estradiol, leuprorelin, tamoxifen and medroxyprogesterone acetate on cell growth and steroid hormone receptors in breast cancer cells. J Cancer Res Clin Oncol 120: 605-609, 1994.

23. Marini L, Iacopino F, Schinzari G, Robustelli della Cuna FS, Mantovani G and Sica G: Direct antiproliferative effect of triptorelin on human breast cancer cells. Anticancer Res 14: 1881-1886, 1994.

24. Sica G, Schinzari G, Angelucci C, Lama G and Iacopino F: Direct effects of GnRH agonists in human hormone-sensitive endometrial cells. Mol Cell Endocrinol 176: 121-128, 2001.

25. Sica G, Iacopino F, Settesoldi D and Zelano G: Effect of leuprorelin acetate on cell growth and prostate-specific antigen gene expression in human prostatic cancer cells. Eur Urol 35 $2-8,1999$

26. Sica G, Zelano G, Settesoldi D and Iacopino F: Regulation of prostate-specific antigen gene expression by an LH-RH analogue in human prostatic cells. Anticancer Res 23: 1283-1287, 2003.

27. Iacopino F, Lama G, Angelucci C and Sica G: Leuprorelin acetate affects ERK1/2 activity in prostate cancer cells. Int J Oncol 29: 237-247, 2006.

28. Angelucci C, Iacopino F, Lama G, et al: Apoptosis-related gene expression affected by a GnRH analogue without induction of programmed cell death in $\mathrm{LNCaP}$ cells. Anticancer Res 24: 2729-2738, 2004.

29. Angelucci C, Lama G, Iacopino F, Ferracuti S, Bono AV, Millar RP and Sica G: GnRH receptor expression in human prostate cancer cells is affected by hormones and growth factors. Endocrine 36: 87-97, 2009.
30. Peterson GL: A simplification of the protein assay method of Lowry et al which is more generally applicable. Anal Biochem 83: 346-356, 1977.

31. Sasaki H, Nio M, Iwami D, Funaki N, Ohi R and Sasano H: Cytokeratin subtypes in biliary atresia: immunohistochemical study. Pathol Int 51: 511-518, 2001.

32. Rashid MG, Sanda MG, Vallorosi CJ, Rios-Doria J, Rubin MA and Day ML: Posttranslational truncation and inactivation of human E-cadherin distinguishes prostate cancer from matched normal prostate. Cancer Res 61: 489-492, 2001.

33. Ito $\mathrm{K}$, Okamoto I, Araki N, et al: Calcium influx triggers the sequential proteolysis of extracellular and cytoplasmic domains of E-cadherin, leading to loss of beta-catenin from cell-cell contacts. Oncogene 18: 7080-7090, 1999.

34. Steinhusen U, Weiske J, Badock V, Tauber R, Bommert K and Huber O: Cleavage and shedding of E-cadherin after induction of apoptosis. J Biol Chem 276: 4972-4980, 2001.

35. Larue L, Ohsugi M, Hirchenhain J and Kemler R: E-cadherin null mutant embryos fail to form a trophoectoderm epithelium. Proc Natl Acad Sci USA 91: 8263-8267, 1994.

36. Nelson WJ, Shore EM, Wang AZ and Hammerton RW: Identification of a membrane-cytoskeletal complex containing the cell adhesion molecule uvomorulin (E-cadherin), ankyrin, and fodrin in Mardin-Darby canine kidney epithelial cells. J Cell Biol 110: 349-357, 1990.

37. Carruba G, Miceli D, D'Amico D, Farruggio R, Comito L, Montesanti A, Polito L and Castagnetta LA: Sex steroids up-regulate E-cadherin expression in hormone-responsive LNCaP human prostate cancer cells. Biochem Biophys Res Commun 212: 624-631, 1995.

38. Aoki M, Hecht A, Kruse U, Kemler R and Vogt PK: Nuclear endpoint of Wnt signaling: neoplastic transformation induced by transactivating lymphoid-enhancing factor 1 . Proc Natl Acad Sci USA 96: 139-144, 1999.

39. Kolligs FT, Kolligs B, Hajra KM, Hu G, Tani M, Cho KR and Fearon ER: Gamma-catenin is regulated by the APC tumor suppressor and its oncogenic activity is distinct from that of beta-catenin. Genes Dev 14: 1319-1331, 2000.

40. Gnanapragasam VJ, Darby S, Khan MM, Lock WG, Robson CN and Leung HY: Evidence that prostate gonadotropin-releasing hormone receptors mediates an anti-tumourigenic response to analogue therapy in hormone refractory prostate cancer. J Pathol 206: 205-213, 2005

41. Montagnani Marelli M, Moretti RM, Mai S, Procacci P and Limonta P: Gonadotropin-releasing hormone agonists reduce the migratory and the invasive behavior of androgen-independent prostate cancer cells by interfering with the activity of IGF-I. Int J Oncol 30: 261-271, 2007.

42. Maudsley S, Davidson L, Pawson AJ, Freestone SH, López de Maturana R, Thomson AA and Millar RP: Gonadotropin-releasing hormone functionally antagonizes testosterone activation of the human androgen receptor in prostate cells through focal adhesion complexes involving Hic-5. Neuroendocrinology 84: 285-300, 2006. 